\title{
Investments into Human Capital as the Factor of Inculcation the Innovations to a Real Economic Sector
}

\author{
Sergei Shmanev \\ Financial University under the Government of the Russian Federation \\ Moscow, Russia \\ E-mail: shmanev_s_v@mail.ru
}

\author{
Ludimila Shmaneva \\ Financial University under the Government of the Russian \\ Federation \\ Moscow, Russia \\ E-mail: shmaneva_luda@mail.ru
}

\author{
Dmitry Morkovkin \\ Financial University under the Government of the Russian \\ Federation \\ Moscow, Russian Federation \\ E-mail: MorkovkinDE@mail.ru
}

\begin{abstract}
The article reviews the transformation conditions of national industry from raw materials direction to a high-tech production and conditions of crossing to the economy, which will be based on knowledge and new technologies. It is shown that the paramount meaning acquire the investments, at first directed into a human fund, science and innovative developments. In the article the authors offer methodical recommendations on creating the model that allows determining the growth of production amount, depending on the assimilations degree and the intensity of their use in production, and the borders of different behavior modes of the considered system also.
\end{abstract}

Keywords-social-economic policy; innovations; investments; human capital; industry; economic growth

\section{INTRODUCTION}

The formation of the innovative industry development strategy in Russia offers the basis of the welfare of the whole country in general. One of the conditions of a high productivity and the quality of a produced output and consequently the competitive ability of the native industry in international market, become the development and inculcation the new technique and technologies to the industrial process. The realization of this strategy is impossible without enough investment to a human capital.

In the presented work there were many problems for the authors. Firstly, to substantiate the theoreticalmethodological approach to the process of investment to a human capital for creation the conditions of crossing the native economy to the innovative direction of evolution. Secondly, to develop the economic-mathematical model, which allows to find and describe quantitatively the regularity of the production growth amount in the real economy sector using the effective applying of a human resource.

\section{METHOD}

The information basis for researches were state statistics data and economic-mathematical methods of forecasting also, which allow to make an analysis and reasonable conclusions about the vector and dynamics of social-economic processes and the accordance of the leading economic policy, and the goals of Russian economic growth, and the crossing of the native industry to the innovative development direction. In the basis of the methodical developments we used system, processing, functional and integration approaches. The theoretical basis of made researches connects to the science literature research, dedicated to the problems of forecasting and modeling of a social-economic development of economy, hi-tech production development, investment-innovative activity of industrial companies, the feature of the investment to a human capital.

The research of the appropriate literature gave the ability to meet with achievements and problems of these activity spaces, and also with methods and methodological approaches for solving the designated problems.

\section{OUTCOME}

The research of modern trends in formation of transformation strategy of native industry with raw-material direction to the hi-tech production and conditions of crossing to economy, which based in knowledge and new technologies.

In specialists' opinion of National economy forecasting institute and Financial university, economy in Russia has a potential for a stable growth with an investment dynamic 
near $8 \%$ with rate about 2, 3-3\% of GNP per year. Besides, this can be possible with a significant proportion of investment, firstly to a human capital, science, innovation development. However, if to make an analysis of economic growth dynamic for last 25 years, we'll see that in general the rates of growth were $0.5 \%$ per year. These indexes testify about stagnancy of our economy and in many experts' opinion, including the forecast of Russian government, in nearest decade it can be expected the growth to 1.4-2 \% at best. This is much less, then the dynamic of the economy growth in developed countries, which is $3.6 \%$ in general nowadays. If such a gap doesn't shrink in 3-4 years, it will naturally become an attenuation of economic and political positions in Russia.

For fracturing these established trends in country the serious structure changes are necessary in the real economy sector. Many economists and politicians connect the success of Russian economy, its structure transformations (especially in a financial system) with the costs dynamic for hydrocarbon and volumes of export. At the same time there should be reminded 2011-2012 years, when the costs growth for oil and oil products didn't help our economy and next accepted sanctions just aggravated the situation: the rates of economic growth came down sharp and we «fell down» to the sanction trap.

In this connection it is unpromisingly to build an economic policy according to the costs growth dynamic for hydrocarbon in our opinion. Besides, it is rather hard to forecast the costs growth in a long-term perspective. So, now many people understand that the costs dynamic for hydrocarbon can't be the basis for a long-term stable growth of national economy and pay attention to such factors of economy growth like labor productivity and rising the competitive ability of native production with help of making high-quality products, so this assumes the crossing to new production technologies. Especially, in such conditions of last year reduction of able-working population the main factor of development can become just the growth of labor productivity and the release of competitive production, so these assume many investments to human capital, science and new modern technologies. It's clear that giving a forecast of influence of a technologic contribution to the rates growth of GNP is not easy, but some experts assume that it can become till $0.4 \%$ of GNP.

In spite of the obviousness of such circumstances and official representatives promises about costs growth for science, education, culture and health care, it is noticed that the expenses reduction for these spaces is getting low. In 2016 the expenses for education shrank for $0.8 \%$ compared to 2015 ; for health care - for $0.5 \%$; expenses for science are in stagnation since 2008 and stay at a level $1.1 \%$ of GNP [1].

To overcome the established trends it is necessary to review drastically the leading structural economic policy of Russian government. In light of the calls, standing in front of the country, one of the main goals can be distinguished the formation of an institutional space, conducive to investments inflow to a human fund and firstly in the real economic sector.
Exactly investments to a human can become the source of economic growth because they create possibilities for development and introduction of new technologies to an industry at last, rising the working labor productivity, release of competitive products, export growth. Of course, the investment to a human capital connects to significant risks, for which calculating and searching for direction of their declining there is not enough experience: till nowadays there are not enough approved and reliable methods of efficiency calculation of investments to a human capital with risk considering, which can allow to give reliable forecast evaluations. In many ways it connects to this that human activity and behavior are complicated connection of desires, feelings, thoughts about processes, passing at a company/ organization, in country/ district, where a human works and lives and depends on level and education quality also, received by him during the whole previous period of life.

Structure formations assume an accounting of out and inner factors, which complex influence forms different effects and regulates social-economic parameters, which determine directions and development dynamic of the country [2]. From that it could be made suggestions that quality structure changes and process of effective knowledge-intensive industry formation should consider volumes of investments to a real economic sector and to a human capital and also the level of using science, staffing, financial and fund potential in industry. Wherein it should be paid serious attention to development and stimulating that spaces of industry, which lost their positions during the restructuring years, firstly we speak about convert industry companies [3].

These structure changes became especially necessary from the moment of Russian entrance to WTO, when the situation aggravated sharp between Russian and foreign companies, which release science-intensive products [4] [5]. In such a situation an ability of heads and people, who are responsible for held reforms, to evaluate correctly and provide the conditions for its development and effective using on time plays a big role, this will allow not just to save, but to increase trade positions of Russian enterprises in international market trades.

As human capital is a complex of inborn abilities, possibilities and features, acquired during a life, which value and quality are hard forecasted, so investment is connected to a high proportion of uncertainty and unpredictability of the results of such kind investments. This unpredictability also follows from that, that economic processes have a complicated structure of a ramified system of interconnections, requiring a stable updating for knowledge and skills for analyzing and calculating. As there are more of them and as wide and deep are them, then easier and more adequate human reacts on any changes, which happen in a society, economy, policy. Besides, the process of investigation and reacting on circumstances are subjective and in many ways are formed because of individual psychological features of a separate person, so it leads to a high level of an uncertainty and a risk of a intellectual potential development. 
Approaches to the efficiency evaluation of investments to a human capital, which is in economic theory, can't consider a versatility, multi-variance of investigation processes of a human personality. An aggravating factor is that human's potential is forming inside personality, not depending on if it invests to itself by himself or investments come from outside space. At the same time physical and psychological features lay: abilities, memory, physical conditions are unique in every person, but are limited and personality potential gets lower with age. So, making of a human capital starts to characterize with decreasing incoming during time, and it follows to a partial costs growth. Besides, the fund formation is getting with the help of human's time. In which connection additional investments to a human capital additional resources of time for a new information assimilation and getting new/additional skills.

Looking for this problem of investment to a human capital and possible earnings it is necessary to consider that factor, that people are not in same conditions: some of them are more gifted by nature, others have more financial opportunities. So, person with limited skills should invest more to himself to equalize opportunities. From our opinion in this situation it is not correct to consider such people like personalities with equal opportunities, not considering material, intellectual, age and life cycles, which compose cultural and historic traditions, and the nearest society influence also, as it was made in Harry Bekker's work.

Anyone has no doubts that increasing of an education level of population brings considerable dividends to the government. Firstly, it is GNP growth because of labor productivity rising. Secondly, it is the quality rising of releasing products and following opportunity to take a certain place in world trade markets and hi-tech productions. Thirdly, it is unemployment declining in the country, because an educated and qualified person has more chances to have a stable high earnings. This is a deposit of a high social stability and crime level declining in society, caused of poverty usually.

Reproduction problem of a working potential, intellect and education level rising as the source of development and innovation using and as an element of a determining vector development of a national economy, is very actual nowadays. So, in spite on complication forecasting of the results of such investments, a benefit is so obvious, that this problem is payed a close attention from economists- scientists, heads of a real economy sector of a different government level, but still is not solved.

We suggest an approach to the investment problem to a human and using a human capital for effective introduction of innovations to a real economic sector from the positions of self-organization, which can be described by non-linear equations. In our reasoning we used a suggestion that an intellectual fund is the main resource of society development. And if this resource is used ineffectively, economy of a real sector gets to the district of "stagnation traps" and further society development will follow the extensive way, and nowadays when the demographic problem in Russia is sharp, this direction will be connected with many difficulties also.
We'll look at the dependency of investment's dynamic to a general human capital, an assimilation of new innovative developments and the volume of productivity, connected with that processes.

In our reasoning we'll proceed from that, that a speed of an assimilation of new knowledges is limited because of human physiology specify. His physical data, health, assimilation skill of big volumes of information get lower with age. Besides, knowledge become stale during time. The speed of assimilation of new information can be showed from the following reasoning as the equation:

$$
v_{i}=-\frac{d I}{\grave{d}}=\frac{d W_{m}}{d \vec{W}}=k_{1} I
$$

The speed of ageing of before assimilated information can be showed like :

$$
v_{1}=\frac{d W_{e}}{d t}=k_{2} I
$$

where I is the value of the investments to an intellectual space, which is considered from working volume rising $\mathrm{I}=\mu \mathrm{Q}$;

Wycr- is the volume of new information, assimilated by the individual person;

\section{Wcm- is the volume of the staled information.}

So, the speed of studying can be showed as a knowledge updating dynamic and to consider the difference between just assimilated and aged information:

$$
V_{i}=\frac{d W}{d t}=\frac{d W_{m . .}-d W_{w}}{\grave{d t}}
$$

The solution of this equation gives us a connection

$$
W=\frac{k_{1} I}{k_{2}-k_{1}}\left(e^{\cdot i t} \cdot e^{\cdot i t}\right)
$$

The growth of productivity volumes will require additional resources. Empirically getting a dependence between the volume industry dynamic and the growth of the necessary resources, we'll get a correlation:

$$
\mathrm{D} R=\frac{k_{\mathrm{D}} \mathrm{D} Q}{k_{i}} e^{\cdot t}
$$

The researches of get dependence gave an opportunity to consider different modes of developing index system behavior, determining the volume growth of production in connection with the level of innovation assimilation and their used intensity in production and also to distinguish the limits of these modes, and following to distinguish the conditions with which the system will be stable.

For calculating the degree accounting of using new resources in production with help of assimilation of additional skills, we'll use the dependence:

$$
\left.\mathrm{W}(t)=W(t-1)+a W(t-1) W_{\ldots .} \cdot W(t-1)\right)
$$

where the level of knowledge growth is.

Build system of equations will look like this: 


$$
\left\{\begin{array}{c}
X(t+1)=\left(p_{0}+p_{1} \mathrm{w}(t)\right) \frac{X \cdot R}{R+g \cdot X} \\
R(t+1)=\frac{k_{3} \Delta Q}{k_{4}} e^{-k_{3} t}+h+\gamma W(t) \\
(5) \\
\mathrm{W}(t)=\frac{k_{1} \cdot \beta \cdot Q}{k_{2}-k_{1}}\left(e^{-k_{2} t}-e^{-k_{1} t}\right)
\end{array}\right.
$$

Where $Q(t)$ - volume of production in connection with new resources using owing to the

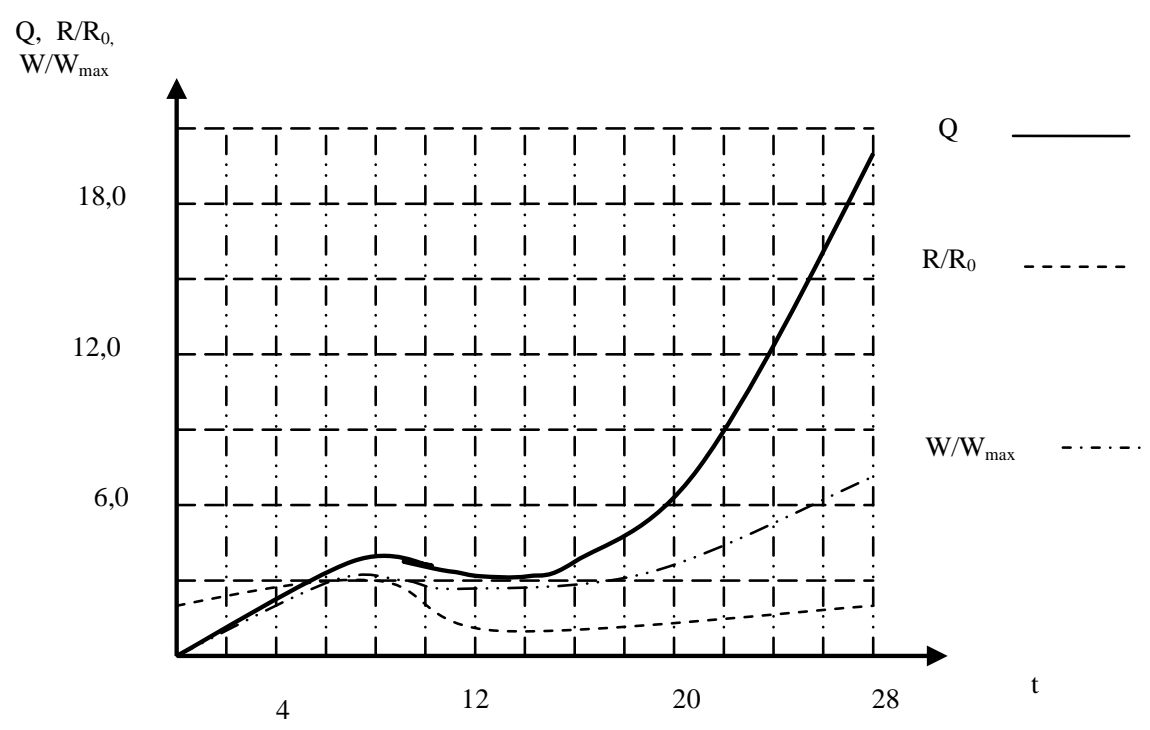

assimilation of new information

- volume of used resources;

- information volume;

- coefficient, determine the changing dynamic of variables;

$\mathrm{g}, \rho, \gamma, \beta$ - coefficients, determine the algorithm of new organizational- economic connections search and forms of dependences;

h- revolving resources.

Fig. 1. The growth of production efficiency in the economy receptive to innovation.

The value $\rho 0$ of determines by temps of extensive volumes' growth of production because

of having the necessary resources.

Experimental researches of the received model showed different modes of events' extension.

So, having a big volume of unused resources and a low level of using the intellectual space, the production volumes will firstly rise high temps, but then the scales of production are falling rather fast and getting low for 4.6 times for 6-7 years. Then the stability comes, and the production is made just from renewable resources. In that cases when the parameters' growth of innovation assimilation in production is observed, the temps' dynamic of the volumes' growth of production with the ending of traditional resources is getting slower, but gets high temps of development because of intellectual constituent, and government stands in the range of high-developed countries because of the technological evolution.

\section{DISCUSSION}

The presented research of investment problem to a human and using a human capital for effective introduction of innovations to a real economic sector and also the model, which is an integration of dependence of investment dynamic to a human capital, the assimilation of new innovative developments and processes of volume production, connected with that, are based on empirical and theoretic methods. The distinctive feature of this research is the development of the methodical approach to investment to a human capital with the aim of providing the conditions, which are necessary for crossing the economy to an innovative direction of evolution.

The reliability of received results is proved by the data of empirical researches and official statistic information, put in the government committee of statistics web-site [6]. 


\section{CONCLUSION}

The presented model allows to make an analysis of many modes of functioning of a separate company, industry, to describe the innovative dynamic and their influence on economic development of a separate district or country in general with accounting of its multilevel structure. Hold researches, made by us, showed that the results of such modeling give an opportunity to make the parameters' limit, which determine the dynamic and stability of interested processes' development, to determine the limits of economic systems' stability and can be used in forming the economic strategy development in different modes of functioning the researched economic systems.

It is possible that we connect excessively optimistic the economic growth in Russia with the investment structure changing and its direction to a human capital (to science, education, innovations also), but nowadays it looks like the only one possible moving.

\section{REFERENCES}

[1] A.N. Clepach, Structure factors of economic growth // Works of the free economic society of Russia. 2016, part 202, pp.25-39.

[2] S. U. Glazyev, Strategy of an advancing development in Russia in conditions of global crisis. W. : Economy. 2011. URL: http://www.glazev.ru

[3] I. Glushenko, The development of financial policy of innovative activity of a company // Finances and credit. 2009, No.18 (354), pp.35-41.

[4] A.A. Altuhanov, Some problems of realization of the law standings "On strategic planning in Russian Federation" // Economy and Enterprise, 2014, No. 7, pp. 100-102.

[5] O. U. Kolomitseva, E. U. Kolesnikova, The perfection of innovative activity of a company based in the mechanism of organization provide // News of the Institute of economy and social administration in Voronezh, 2015, No. 4, pp.63-68.

[6] D. Morkovkin, S. Shmanev, L. Shmaneva, Problems and Trends in Innovative Transformation of Russian Economy and Infrastructure Development / // Advances in Economics, Business and Management Research. Volume 32. 3rd International Conference on Economics, Management, Law and Education (EMLE 2017). Atlantis Press, 2017, pp. 25-35. URL: https://www.atlantis-press.com/proceedings/emle$17 / 25888249$ 